\title{
Set theoretical and algebraic model for redundancies in the genetic code
} Karl Heuer*

\author{
Address: University of Hamburg, Hamburg, Germany \\ Email: Karl Heuer* - kmh@exmpl.de \\ * Corresponding author
}

from BioSysBio 2007: Systems Biology, Bioinformatics and Synthetic Biology Manchester, UK. II-13 January 2007

Published: 8 May 2007

BMC Systems Biology 2007, I (SuppI I):P34 doi: I0.I I86/I752-0509-I-SI-P34

This abstract is available from: http://www.biomedcentral.com/I752-0509/I?issue=SI

(c) 2007 Heuer; licensee BioMed Central Ltd.

\section{Background}

Codons are similar to syllogisms. Each codon has a complement - an anticodon - and syllogisms have such too. Another point is that codons and syllogisms consist of 3 of 4 possible building blocks. So 64 syllogisms should exist, but only 19 make sense. Each syllogism is a set operation, which I can represent with Shegalkin-Polynomials [1]. This needs a continuous view, which is ordinary in biological systems. It accrues matrices with special properties. They are self-similar, that means they can be generated with a tensor product of their own. Other methods work with power sets or multidimensional tetrahedral numbers. Because of these different generation methods it can be shown, that the matrices can be generated with a cellular automaton. Each cellular automaton is producible with a linear automaton [2-7], so there is an other aspect of dependence of the this model and decoding of amino acids. The decoding of amino acids follows the rules of a linear automaton. In order to combine the fields of syllogisms and amino acids a different representation for them is used - a tetrahedral grid. This is possible, because the number of syllogisms and amino acids is not only a square number, it is also a triangle number. Prof. Dr. Franke's matrices [8] let me construct such a grid, because of their structure of a Pascal triangle.

\section{Results}

My work shows the existence of bijective mappings between syllogisms and amino acids (see Figures 1 and 2). This is discernible with the tetrahedral grid. The smaller triangles in the grid can not be ordered arbitrarily without losing information. It follows because of triangle rotations. Nevertheless the triangles of redundant coded amino acids with degeneracy 6 (arginine, leucine and serine) seem to be ordered arbitrarily in the grid. Their distribution in the grid fits to model of family boxes $[9,10]$ and to a dynamical model by Magini and Hornos [11]. My model has some other similarities with the last one; for example a basic approach with a Platonic solid (tetrahedron and octahedron). Mathematical invalid syllogisms are very important in my model too, because in strong logics they do not work every time, but they are useful in biology.

\section{Conclusion}

The bijective mapping could explain Prof. Dr. Freeland's presumption [12], that fewer amino acids existed in the past. Mathematical invalid syllogisms are very interesting here. But the further work is also going to aim on a more intensive test of the position of the amino acids and syllogisms. The positions seem to have something in common with chemical properties. This would help to explain that amino acids, which drift from the genetic code, have similar chemical properties i.e. hydrophobia. Prof. Dr. Freeland wrote about this [12] too. Shegalkin-Polynomials shall be used here. 


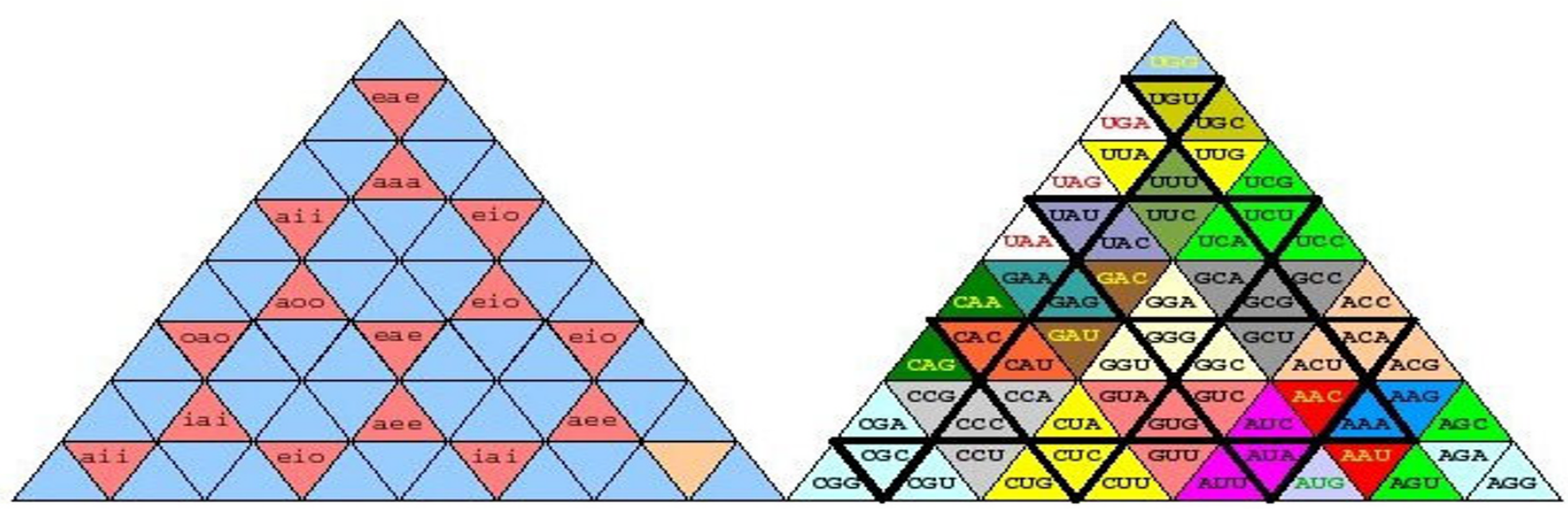

Figure I

Bijective mapping with tetrahedral grid of syllogisms and of coded amino acids. Red marked triangles in the left tetrahedral grid are valid syllogisms. Black framed triangles mean that the amino acid with the same colour is assigned to one syllogism. The triangles with red font are stop-sequences and are not assigned to a syllogism. The triangle with green font is the start-sequence and is not assigned to a syllogism (Gödel, DeMorgan). The other triangles with yellow font are not assigned to a syllogism in the left tetrahedral grid. They are assigned to so called invalid syllogisms i.e. darapti.

$$
\psi^{\{3\}}=\left(\begin{array}{llllllll}
\mathbf{1} & 0 & 0 & 0 & 0 & 0 & 0 & 0 \\
\mathbf{1} & \mathbf{1} & 0 & 0 & 0 & 0 & 0 & 0 \\
\mathbf{1} & 0 & \mathbf{1} & 0 & 0 & 0 & 0 & 0 \\
1 & \mathbf{1} & \mathbf{1} & \mathbf{1} & 0 & 0 & 0 & 0 \\
1 & 0 & 0 & 0 & \mathbf{1} & 0 & 0 & 0 \\
1 & 0 & \mathbf{1} & 0 & \mathbf{1} & 0 & 1 & 0 \\
1 & 1 & 1 & 1 & 1 & 1 & 1 & 1
\end{array}\right)
$$

\section{Figure 2}

Coefficient matrix of a boolean function with three variables. This matrix is an example for Prof. Dr. Franke's matrices [8], which are used in my work.

\section{References}

I. Shegalkin II: Die Arithmetisierung der symbolischen Logik. Mat co 1928:3II-377.

2. Wolfram S, Farmer JD, Toffoli T: Cellular Automata. Proceedings of an Interdisciplinary Workshop. Physica D 1984, I0D(I and 2):.

3. Dewdney AK: The Planiverse Poseidon Press; 1984.

4. Hayes B: Tabellenkalkulation. In Spektrum der Wissenschaft Sonderheft Computer-Kurzweil II; 1988:46-52.

5. Hayes B: Endliche Automaten. In Spektrum der Wissenschaft Sonderheft Computer-Kurzweil II; 1988:53-59.

6. Hayes B: Zelluläre Automaten. In Spektrum der Wissenschaft Sonderheft Computer-Kurzweil II; 1988:60-67.

7. Dewdney AK: Lineare Automaten. In Spektrum der Wissenschaft Sonderheft Computer-Kurzweil II; 1988:68-73.

8. Franke D: Sequentielle Systeme. Vieweg Verlag; 1994

9. Osawa S, Jukes TH, Watanabe K, Muto A: Microbiol Rev 1992, 56:229-264.
10. Osawa S: Evolution of the Genetic Code. Oxford: Oxford University Press; 1995.

II. Magini M, Hornos JEM: A Dynamical System for the Algebraic Approach to the Genetic Code. Brazilian Journal of Physics 2003, 33(4):

12. Freeland SJ, Hurst LD: Der raffinierte Code des Lebens. In Spektrum der Wissenschaft Dossier Das neue Genom; 2006:18-25.
Publish with Biomed Central and every scientist can read your work free of charge

"BioMed Central will be the most significant development for disseminating the results of biomedical research in our lifetime. "

Sir Paul Nurse, Cancer Research UK

Your research papers will be:

- available free of charge to the entire biomedical community

- peer reviewed and published immediately upon acceptance

- cited in PubMed and archived on PubMed Central

- yours - you keep the copyright 